\title{
PRODUÇÃO DE BANANEIRA, CULTIVAR D'ANGOLA, CONSORCIADA COM AÇAIZEIRO SOLTEIRO EM DIFERENTES ARRANJOS DE PLANTIO
}

\author{
Ueliton Oliveira de Almeida ${ }^{1}$, Romeu de Carvalho Andrade Neto², Aureny Maria Pereira Lunz², \\ Marines Cades ${ }^{1}$, David Aquino da Costa ${ }^{1}$, James Maciel de Araújo ${ }^{1}$, Davair Lopes Teixeira Júnior ${ }^{3}$, \\ Maria Júlia da Silva Rodrigues ${ }^{1}$
}

\begin{abstract}
RESUMO - O objetivo deste trabalho foi avaliar o desempenho agronômico de bananeira, cultivar D'angola, consorciada com açaizeiro solteiro em diferentes arranjos. O experimento foi conduzido em blocos casualizados completos com quatro repetições e seis plantas por parcela. Os tratamentos foram: T1 - bananeira (3 x 3 $\mathrm{m})$; T2 - bananeira (3 x $2 \mathrm{~m})$ com açaizeiro solteiro (3 x $4 \mathrm{~m})$; T3 - bananeira (3 x $3 \mathrm{~m})$ com açaizeiro solteiro (3 x $4 \mathrm{~m})$; T4 - bananeira $(4 \times 2 \times 2 \mathrm{~m})$ com açaizeiro solteiro (6 x $3 \mathrm{~m})$, e; T5 - bananeira (4 x 2 × 2 m) com açaizeiro solteiro ( 4 × 2 x $3 \mathrm{~m}$ ). Foram avaliadas as características de crescimento e desenvolvimento, produção e qualidade físico-químicas dos frutos. As médias foram comparadas pelo teste de Tukey a 5\% de probabilidade. As características de crescimento e desenvolvimento, produção e qualidade físico-químicas não sofreram interferência do consórcio com açaizeiro solteiro, com exceção para o perímetro do pseudocaule, produtividade e quantidade de folhas ativas na colheita. As maiores produtividades foram obtidas em plantios mais adensados, independentemente do sistema de cultivo.
\end{abstract}

Palavras chave: densidade de plantio, espaçamento, Euterpe precatoria Mart., Musa spp.

\section{PRODUCTION OF BANANA, CULTIVAR D'ANGOLA, INTERCROPPED WITH AÇAI SINGLE IN DIFFERENT PLANTING ARRANGEMENTS}

\begin{abstract}
The objective of this work was to evaluate the agronomic performance of banana, cultivar D'angola, consorted with açai single in different arrangements. The experiment was conducted in a randomized complete block with four replicates and six plants per plot. The treatments were: T1 - banana (3 x $3 \mathrm{~m})$; T2 - banana tree (3 $\times 2 \mathrm{~m}$ ) with açai single (3 $\times 4 \mathrm{~m})$; T3 - banana tree ( $3 \times 3 \mathrm{~m})$ with açai single ( $3 \times 4 \mathrm{~m})$; T4 - banana $(4 \times 2 \times 2 \mathrm{~m})$ with açai single $(6 \times 3 \mathrm{~m})$, and; T5 - banana $(4 \times 2 \times 2 \mathrm{~m})$ with açai single $(4 \times 2 \times 3 \mathrm{~m})$. The characteristics of growth and development, production and physical-chemical quality of fruits were evaluated. The averages were compared by the Tukey test at 5\% probability. The characteristics of growth and development, production and physical-chemical quality were not affected by the consortium with açai single, except for the perimeter of the pseudostem, yield and the number of leaves active at harvest. The highest yields were obtained in more densified plantations, independently of the cultivation system.
\end{abstract}

Keywords: Musa spp., Euterpe precatoria Mart., spacing, planting density.

Trabalho obtido a partir da dissertação de mestrado do primeiro autor

${ }^{1}$ Engenheiro Agrônomo (a) do Programa de Pós-Graduação em Agronomia da Universidade Federal do Acre, BR 364, Km 04, Distrito Industrial, CEP 69.920-900, Rio Branco-AC. E-mail para correspondência: uelitonhonda5@hotmail.com.

${ }^{2}$ Pesquisador (a) da Embrapa Acre, BR 364, Km 14, CEP 69.908-970, Rio Branco-AC.

${ }^{3}$ Docente do Instituto Federal do Acre. Campus Xapuri. Rua Coronel Brandão, no 1.622, Centro, CEP: 69.930-000. 


\section{INTRODUÇÃO}

O cultivo adensado de fruteiras, prática agronômica essencial para os agricultores, promove melhor aproveitamento da área, mão de obra e insumos, além de aumentar a produtividade, desde que a cultura seja implantada em locais que apresentem condições edafoclimáticas favoráveis ao seu pleno desenvolvimento (Scarpare Filho \& Kluge, 2001).

O espaçamento entre bananeiras pode variar de acordo com a cultivar a ser explorada, local de implantação e nível tecnológico empregado, podendo ser de 3,0 x 2,0 m e 3,0 x 2,5 m em fileiras simples para as cultivares D'angola e Terrinha, além de fileiras duplas de $4,0 \mathrm{x}$ $2,0 \times 2,0 \mathrm{~m}$ e 4,0 × 2,0 x 3,0 m, que permitem melhor aproveitamento da área e uso de consórcio (Ferreira et al., 2016a), e com isso pode evitar a competição por água, luz e nutrientes, sem comprometer os rendimentos potenciais de cada cultura.

Geralmente, a maior densidade de plantas influencia em algumas características físicas e de produção da bananeira, como a massa do cacho, comprimento e diâmetro dos frutos (Moura et al., 2002). Entretanto, a produtividade aumenta significativamente devido a maior quantidade de plantas por hectare (Cayón et al., 2004; Cavalcante et al., 2014; Ulloa Cortazar et al., 2017; Prata et al., 2018).

A cultura da banana pode ser produzida em diversos tipos de consórcios, tanto como cultura principal, onde normalmente são utilizadas espécies alimentícias anuais, como feijão comum, milho, arroz, mandioca ou plantas de cobertura, quanto de forma secundária com plantas perenes, como o cafeeiro, dendezeiro, coqueiro, cupuaçuzeiro e cacaueiro. Além disso, também pode ser utilizada como componente em sistemas agroflorestais (Alves et al., 2015; Ferreira et al., 2016b).

O consórcio de fruteiras com culturas anuais, perenes e semi-perenes representam alternativas adequadas para o uso da área e uma forma importante para a recuperação de áreas degradadas. Este sistema possibilita melhores combinações de diferentes espécies agrícolas, diversificando a produção, aumentando a renda dos pequenos produtores e ainda é fundamental para o crescimento inicial de culturas que necessitam de sombreamento provisório no período que antecede a produção, como o cupuaçuzeiro e cacaueiro (Ferreira et al., 2016b; Sales et al., 2018).
A bananeira (Musa spp.) e o açaizeiro solteiro (Euterpe precatoria Mart.) são duas fruteiras estratégicas para consórcio pela grande demanda dos consumidores e por apresentar potencial social, econômico e ambiental para as condições da Amazônia Brasileira. No Estado do Acre, a bananeira é a principal fruteira cultivada, com montante de $106.268 \mathrm{t}$ de frutos produzidos em uma área colhida de 8.100 ha, enquanto que o extrativismo de açaí é estimado em 5.568 t, com contribuição nacional em torno de 2,58\% (IBGE, 2018).

Apesar da região Norte apresentar condições edafoclimáticas favoráveis ao cultivo da bananeira, o baixo nível tecnológico empregado pela maioria dos produtores e a densidade de plantio abaixo da indicada para a cultura reflete, principalmente, em rendimento insatisfatório e qualidade inadequada das frutas ao consumidor (Nogueira et al., 2017). O objetivo deste trabalho foi avaliar as características agronômicas de bananeira terra, cv. D’angola, em monocultivo e consorciada com açaizeiro solteiro em diferentes arranjos de plantio, no primeiro ciclo de produção.

\section{MATERIALE MÉTODOS}

O experimento foi conduzido no campo experimental da Embrapa Acre, em Rio Branco-AC, entre março de 2012 e maio de 2014. O clima da região é Am (quente e úmido), segundo a classificação de Köppen, com temperaturas máxima de $30,9^{\circ} \mathrm{C}$ e mínima de $20,8^{\circ} \mathrm{C}$, precipitação anual de 1.648,9 mm e umidade relativa de $83 \%$.

O solo da área experimental foi classificado como Argissolo Vermelho Amarelo distrófico, de textura média e bem drenado com as seguintes características físicoquímicas, na camada de 0-20 cm: $\mathrm{pH}\left(\mathrm{H}_{2} \mathrm{O}\right)=4,52$; Ca $=1,4 \mathrm{cmol}_{\mathrm{c}} \mathrm{dm}^{-3} ; \mathrm{Mg}=0,79 \mathrm{cmol}_{\mathrm{c}} \mathrm{dm}^{-3} ; \mathrm{K}=0,32 \mathrm{cmol}_{\mathrm{c}}$ $\mathrm{dm}^{-3} ; \mathrm{Al}+\mathrm{H}=4,43 \mathrm{cmol}_{\mathrm{c}} \mathrm{dm}^{-3} ; \mathrm{P}$ (remanescente) $=9,91$ $\mathrm{mg} \mathrm{L}^{-1}$; saturação por bases $=36,18 \%$; areia $=315,42$ $\mathrm{g} \mathrm{kg}^{-1}$; silte $=319,88 \mathrm{~g} \mathrm{~kg}^{-1}$; argila $=364,70 \mathrm{~g} \mathrm{~kg}^{-1}$. Os dados climáticos estão descritos na Figura 1.

O delineamento utilizado foi de blocos casualizados completos com quatro repetições, sendo avaliadas seis plantas de banana por parcela, com os tratamentos dispostos da seguinte forma: T1 - monocultivo de bananeira em 3 x 3 m (1.111 plantas ha-1 $^{-1}$; T2 - bananeira em 3 x 2 m (1.666 plantas ha ${ }^{-1}$ ) com açaizeiro solteiro em 3 x 4 m (833 plantas ha $\left.{ }^{-1}\right)$; T3 - bananeira em 3 x $3 \mathrm{~m}$ (1.111 plantas ha $\left.{ }^{-1}\right)$ com açaizeiro solteiro em 3 
x 4 m (833 plantas ha ${ }^{-1}$ ); T4 - bananeira em 4 x 2 x 2 m (1.666 plantas ha-1) com açaizeiro solteiro em 6 x 3 m (555 plantas ha-1), e; T5 - bananeira em 4 × 2 × 2 m (1.666 plantas ha-1) com açaizeiro solteiro em 4 x 2 x 3 m (1.111 plantas ha-1) (Figura 2). A área de cada parcela foi composta de $180 \mathrm{~m}^{2}$, onde se avaliou seis plantas centrais.
As covas foram preparadas aos 30 dias antes do plantio nas dimensões de 0,4 x 0,4 x 0,4 m. Na adubação de plantio colocou-se $5 \mathrm{~L}$ de esterco de galinha, 600 g da formulação 10-10-10 (NPK), 800 g de calcário dolomítico e $50 \mathrm{~g}$ de micronutrientes (FTE BR 12).

Em 21 de março de 2013 foi realizado o plantio das mudas de bananeira terra, do tipo “pedaço de rizoma”,

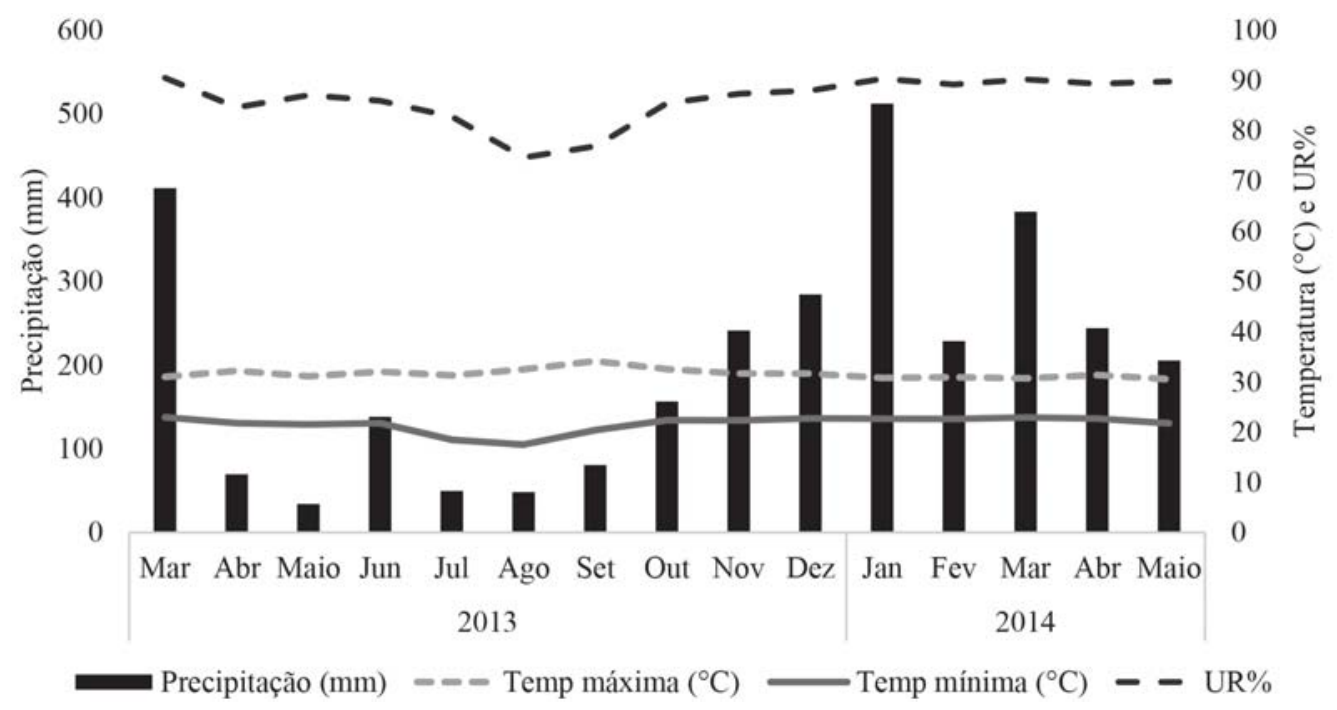

Figura 1 - Dados climáticos registrados durante o período de avaliação do experimento de consórcio de bananeira terra, cv. D'angola, com açaizeiro solteiro em diferentes arranjos de plantio, de março de 2013 a maio de 2014. Rio Branco, AC.

T1

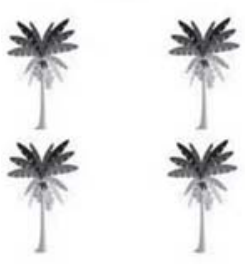

T4

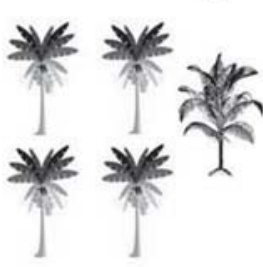

T2

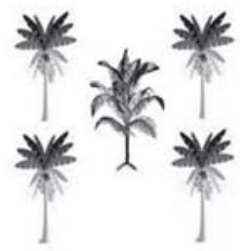

T3
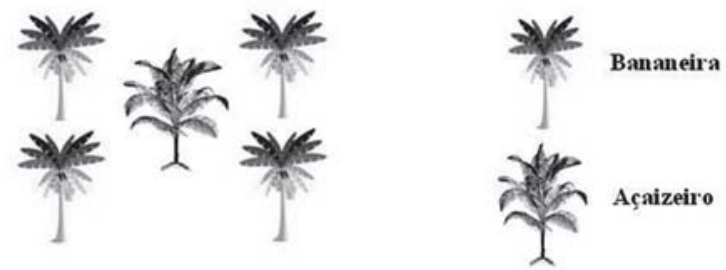

T5
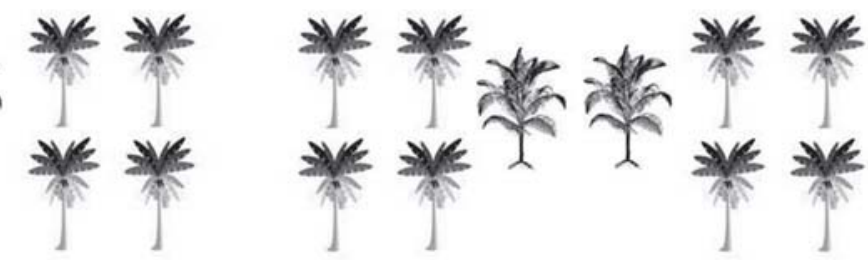

Figura 2 - Representação esquemática do monocultivo e consórcio de bananeira com açaizeiro em diferentes arranjos de plantio. 
cv. D’angola (ABB), com massa aproximada de $400 \mathrm{~g}$ ( $\pm 50 \mathrm{~g}$ ), previamente tratadas em calda de carbofuran, a fim de evitar o ataque da broca do rizoma (Cosmopolites sordidus Germar). As mudas de açaizeiro solteiro foram plantadas aos oito meses após o plantio da bananeira, apresentando, em média: duas ou três folhas iniciais; altura de 21,82 cm; diâmetro do estipe de 14,30 mm, e; diâmetro da copa de $44 \mathrm{~cm}$. No momento do plantio, as bananeiras apresentavam altura de $160 \mathrm{~cm}$, perímetro do pseudocaule a $30 \mathrm{~cm}$ do solo de 39,68 cm e 17 folhas ativas em média.

Os tratos culturais do bananal foram realizados de acordo com Ferreira et al. (2016a). As adubações de cobertura foram realizadas com base na análise de solo e recomendação específica de cada cultura. O experimento foi conduzido sem o uso de irrigação.

As variáveis avaliadas foram: altura da planta na inserção da inflorescência, perímetro do pseudocaule a $30 \mathrm{~cm}$ do solo e número de folhas ativas no florescimento, sendo avaliadas na época da floração, em média, aos 297,93 dias após o plantio (Tabela 1), ciclo da cultura (número de dias do plantio ao florescimento, do florescimento à colheita e do plantio à colheita), número de folhas ativas no florescimento e na colheita, massa do cacho, massa do engaço, massa das pencas, número de pencas e de frutos por cacho, produtividade (multiplicação da massa do cacho pela densidade de plantas), diâmetro e comprimento do fruto (média de cinco frutos da segunda penca) e características físicoquímicas (potencial hidrogeniônico $(\mathrm{pH})$, acidez titulável (AT), sólidos solúveis totais (SST) e relação sólidos solúveis totais/acidez titulável (RATIO), analisados na colheita, aos 390,08 dias após o plantio, em média (Tabela 1). A colheita foi iniciada em 07 de fevereiro de 2014.

Os dados foram submetidos à análise de variância (teste F) e as médias foram comparadas pelo teste de Tukey a 5\% de probabilidade. As análises foram realizadas pelo programa computacional Sistema para Análise de Variância - SISVAR (Ferreira, 2011). Os dados originais do número de dias do plantio ao florescimento e número de folhas ativas no florescimento, apresentados na Tabela 1, foram transformados por CosX+10 e LogX, respectivamente.

\section{RESULTADOS E DISCUSSÃO}

Não foram observadas diferenças significativas entre os tratamentos para a altura da planta, ciclo de produção (número de dias do plantio ao florescimento; número de dias do florescimento à colheita e número de dias do plantio à colheita), tampouco para o número de folhas ativas na floração. Entretanto, detectou-se diferença estatística para o perímetro do pseudocaule e número de folhas ativas na colheita (Tabela 1).

As bananeiras em monocultivo (3 $\mathrm{x} 3 \mathrm{~m}$ ), assim como as bananeiras no espaçamento de 3 x $3 \mathrm{~m}$ consorciada com açaizeiro solteiro em 3 x $4 \mathrm{~m}$ apresentaram maior perímetro do pseudocaule, com 62,60 cm (Tabela 1). Esses resultados são estatisticamente semelhantes aos 59,98 cm encontrados por Cavalcante et al. (2014) e inferiores aos $74 \mathrm{~cm}$ obtidos por Faria et al. (2010), ambos com a cultivar D'angola no primeiro ciclo de produção e em espaçamento de 3 x $3 \mathrm{~m}$. Resultado superior $(77,57 \mathrm{~cm})$ também foi obtido por Dantas (2010) em espaçamento de 3 x 2 m e no primeiro ciclo, com a mesma cultivar deste estudo.

Em condições de plantios menos adensados, as bananeiras tendem a apresentar maior perímetro do pseudocaule devido à competição por luz, espaço e por outros fatores não serem limitantes para o crescimento da planta. Essa variável é importante por garantir a sustentação da planta no campo, sobretudo das que possuem cachos maiores e mais pesados. Assim, as plantas que apresentam maior diâmetro são as desejáveis por proporcionar maior capacidade de suporte à planta (Bolfarini et al., 2014) e ao próprio cacho (Silva et al., 2016).

As bananeiras no espaçamento de $4 \times 2 \times 2$ m consorciadas com açaizeiro solteiro em 6 x $3 \mathrm{~m}$, assim como as bananeiras em 4 × 2 × 2 m com açaizeiro solteiro em 4 x 2 x 3 m apresentaram em torno de sete folhas vivas na colheita, apresentando, portanto, valores inferiores aos demais tratamentos (Tabela 1). Em espaçamentos duplos, o número de folhas na colheita pode ter sido menor devido aos efeitos abrasivos entre elas, competição entre plantas por espaço e senescência natural.

Em relação ao ciclo, o mesmo comportamento foi observado para o plátano Dominico-Hartón em diferentes densidades e arranjos de plantio, sem apresentar diferença significativa (Cayón et al., 2004), bem como no cultivo de banana comprida verdadeira em sistemas de espaçamentos, no primeiro ciclo de produção, na região da Zona da Mata Sul de Pernambuco (Moura et al., 2002). 
Tabela 1 - Avaliação da altura da planta (APL), perímetro do pseudocaule (PPS), número de dias do plantio ao florescimento (NDPF), do florescimento à colheita (NDFC), do plantio à colheita (NDPC), número de folhas ativas no florescimento (NFAF) e número de folhas ativas na colheita (NFAC) de bananeira terra, cv. D'angola em monocultivo e consorciada com açaizeiro solteiro em diferentes arranjos de plantio. Rio Branco - AC, 2014

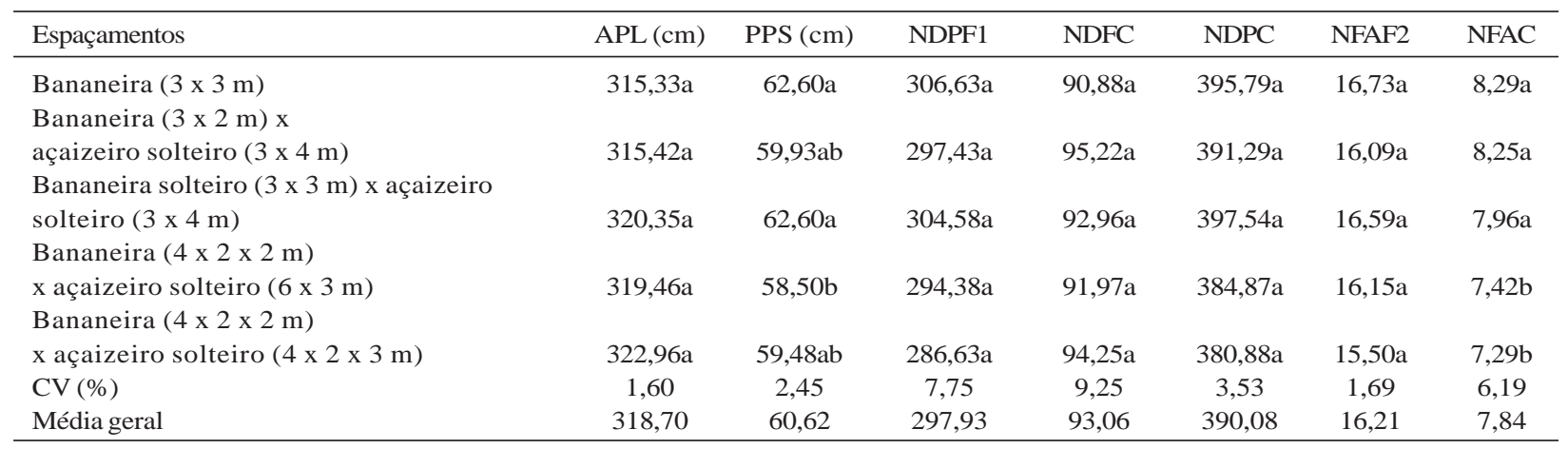

Médias seguidas de mesma letra não diferem entre si pelo teste Tukey $(\mathrm{P}>0,05)$.

${ }^{1}$ Dados originais transformados em $\operatorname{Cos} \mathrm{X}+10$.

${ }^{2}$ Dados originais transformados em LogX.

As bananeiras levaram, em média, 297,93 dias para emitirem a inflorescência nos diferentes arranjos de cultivo. Para o número de dias do florescimento à colheita, verificou-se que as bananeiras consumiram 93 dias, em média, para completar o pleno desenvolvimento fisiológico dos frutos. Para o ciclo, foram necessários, em média, 390,08 dias para que o ciclo entre o plantio e a colheita fosse atingido (Tabela 1). Coelho et al. (2013), ao trabalharem com diferentes lâminas de irrigação em cultivares de bananeira tipo Terra, verificaram que o primeiro ciclo de produção da cv. D’angola foi de 384 dias, sendo estatisticamente semelhante ao encontrado neste estudo.

O ciclo de produção está de acordo com os especificados por Ferreira et al. (2016a), que descrevem que a cv. D'angola produz entre 390 e 420 dias após o plantio. Porém, Cavalcante et al. (2014) obtiveram ciclos que variaram entre 338 a 377 dias, em diferentes espaçamentos avaliados nas condições do estado do Acre, o que pode ter sido influenciado pelas condições climáticas e práticas culturais.

O número de folhas viáveis na floração (50\% da área verde) foi de 16,21, em média (Tabela 1), sendo estatisticamente inferior à obtida por Dantas (2010), com de 17,60 unidades e maior que a encontrada por Faria et al. (2010), com 14,20. Cavalcante et al. (2014) também observaram resultados inferiores, com valores médios de 10 folhas em monocultivo com diferentes espaçamentos de plantio e com 15 folhas em consórcio com seringueira, utilizando a cv. D’angola. Esta variável reflete na qualidade física das bananas e na massa do cacho, e consequentemente, no rendimento potencial da cultivar, uma vez que estas são responsáveis pela área fotossintética da planta e translocação dos fotoassimilados destinados aos frutos.

Güerere-Pereira et al. (2008) relatam que para a cultivar de plátano Hartón produzir frutos com boa qualidade, em termos de quantidade, massa e tamanho, é necessário a presença de 12 folhas funcionais na época do florescimento. Considerando estes dados, verifica-se que o número médio de 16,21 folhas vivas, obtidas na floração, foi suficiente para o desenvolvimento normal das bananas da cv. D'angola em monocultivo e em consórcio com açaizeiro solteiro.

Entre o florescimento e a colheita ocorreu redução severa no número de folhas, em mais de $50 \%$, em todos os tratamentos. A redução das folhas entre a floração e a colheita ocorre devido à senescência natural, à presença de doença e à translocação dos fotoassimilados para a formação dos frutos, que passam a ser dreno preferencial da planta (Silva et al., 2006). Além disso, o número de folhas ativas na floração apresenta correlação significativa negativa com o número de folhas na colheita (Arantes et al., 2010), o que demonstra a redução em mais de $50 \%$ das folhas até a colheita. 
Na Tabela 2, estão expressos os resultados referentes à produção e qualidade física de frutos de bananeira, onde apenas a produtividade foi influenciada pelos tratamentos.

A massa do cacho oscilou de 17,86 kg a 19,83 kg em ambas as formas de cultivo (consórcio e monocultivo). Esses resultados foram semelhantes aos $16,50 \mathrm{~kg}$ encontrados por Dantas (2010) e superiores aos obtidos por Faria et al. (2010), Cavalcante et al. (2014) e por Prata et al. (2018), os quais constataram valores médios de 12,00, 10,77 e 11,30 kg por cacho, respectivamente, ambos com a cultivar D'angola. De acordo com estudos realizados por estes autores, os cachos dessa cultivar apresentam massa entre 9,30 e 16,50 kg, o que depende do sistema de cultivo adotado, locais de produção, espaçamentos, clima e tratos culturais. Segundo Nogueira et al. (2017), a realização dos tratos culturais é indispensável para que o bananicultor obtenha boas produtividades e lucratividade, e com frutos de melhor qualidade.

A massa do engaço não foi influenciada pelas formas de cultivo (monocultivo ou consorciada em diferentes espaçamentos) com média de 1,21 kg referente à média de $6,45 \%$ do peso do cacho. Os resultados encontrados por Faria et al. (2010), com 1,30 kg, são semelhantes aos obtidos neste estudo.

A massa das pencas apresentou média de 17,5 $\mathrm{kg}$ por cacho. Esse resultado é superior aos obtidos por Faria et al. (2010), Coelho et al. (2013) e Cavalcante et al. (2014), os quais encontraram massa média de $10,70,10,18$ e 14,70 kg por cacho, respectivamente. Arantes et al. (2010) reportam que a massa das pencas está fortemente associada com o peso do cacho de plátanos, o que apresenta máxima correlação direta e indica uma possível ligação genética entre esses caracteres.

O número de pencas e de frutos por cacho, variáveis essas essenciais no melhoramento genético da bananeira, foi de 6,94 e 41,03 unidades, em média, respectivamente. Resultados semelhantes foram obtidos por Faria et al. (2010) para o número de pencas (7 un.) e inferiores para a quantidade de frutos (36 un.).

O número de pencas, assim como o tamanho, a massa e a quantidade de frutos contida nela influenciam a massa do cacho, sendo um critério levado em conta pelo bananicultor na escolha de uma cultivar ou na adoção de um determinado tipo de manejo.

Em relação à produtividade, observa-se que os cultivos mais adensados, com espaçamentos de $3 \mathrm{x}$ 2 m e 4 × 2 × 2 m (1666 plantas ha-1) foram superiores $(\mathrm{p}<0,05)$ aos plantios com menores quantidades de plantas, ou seja, aqueles com distanciamento de $3 \mathrm{x}$ $3 \mathrm{~m}$ (1111 plantas ha ${ }^{-1}$ ) (Tabela 2). A produtividade oscilou entre 21,77 e 30,90 tha-1 para a menor e maior densidade de plantas, respectivamente. Faria et al. (2010) e Cavalcante et al. (2014) obtiveram produtividade

Tabela 2 - Valores da massa do cacho (MCA), massa do engaço (MEN), massa das pencas (MPE), número de pencas por cacho (NPC), número de frutos por cacho (NFC), produtividade ( $\mathrm{t} \mathrm{ha}^{-1}$ ), diâmetro do fruto (DF) e comprimento do fruto (CF) de bananeira terra, cv. D'angola, em monocultivo e consorciada com açaizeiro solteiro em diferentes arranjos de plantio. Rio Branco, AC. 2014

\begin{tabular}{|c|c|c|c|c|c|c|c|c|}
\hline Espaçamentos & MCA (kg) & MEN(kg) & MPE(kg) & NPC(un.) & NFC(un.) & Prod.(t ha-1) & $\mathrm{DF}(\mathrm{mm})$ & $\mathrm{CF}(\mathrm{cm})$ \\
\hline Bananeira ( 3 x 3 m) & $19,60 \mathrm{a}$ & $1,21 \mathrm{a}$ & $18,38 \mathrm{a}$ & $7,25 a$ & $42,67 a$ & $21,77 b$ & $50,70 a$ & $26,78 a$ \\
\hline Bananeira $(3 \times 2 \mathrm{~m}) \mathrm{x}$ & & & & & & & & \\
\hline Açaizeiro solteiro ( $3 \times 4 \mathrm{~m})$ & $17,97 a$ & $1,12 \mathrm{a}$ & $16,89 a$ & $6,71 \mathrm{a}$ & $38,71 \mathrm{a}$ & 29,93a & $51,18 a$ & $27,40 \mathrm{a}$ \\
\hline Bananeira $(3 \times 3 \mathrm{~m}) \mathrm{x}$ & & & & & & & & \\
\hline açaizeiro solteiro ( $3 \times 4 \mathrm{~m})$ & 19,83a & $1,26 \mathrm{a}$ & $18,57 \mathrm{a}$ & $7,17 \mathrm{a}$ & 43,03a & $22,03 b$ & $50,51 a$ & $27,42 \mathrm{a}$ \\
\hline $\begin{array}{l}\text { Bananeira }(4 \times 2 \times 2 \mathrm{~m}) \text { x açaizeiro } \\
\text { solteiro }(6 \times 3 \mathrm{~m})\end{array}$ & $17,86 a$ & $1,25 a$ & $16,61 \mathrm{a}$ & 6,88a & $41,29 a$ & $29,76 a$ & $49,89 a$ & $27,67 a$ \\
\hline $\begin{array}{l}\text { Bananeira }(4 \times 2 \times 2 \mathrm{~m}) \times \text { açaizeiro } \\
\text { solteiro }(4 \times 2 \times 3 \mathrm{~m})\end{array}$ & $18,55 a$ & $1,23 a$ & $17,32 \mathrm{a}$ & $6,71 a$ & $39,42 a$ & $30,90 a$ & $50,48 a$ & $27,83 a$ \\
\hline CV (\%) & 5,51 & 7,17 & 6,21 & 4,18 & 5,85 & 5,71 & 1,67 & 1,95 \\
\hline Média geral & 18,76 & 1,21 & 17,56 & 6,94 & 41,03 & 26,88 & 50,55 & 27,42 \\
\hline
\end{tabular}

Médias seguidas de mesma letra não diferem entre si pelo teste de Tukey ( $\mathrm{p}>0,05)$. 
inferiores ao do presente trabalho, no espaçamento de 3 x 3 m, com 11,54 e 13,32 t ha-1. Por outro lado, Dantas (2010) demonstrou rendimento bem próximo, com 27,5 tha ${ }^{-1}$ quando usou espaçamento de $3 \times 2$ $\mathrm{m}$. Vários trabalhos demonstram que com o aumento da densidade de plantio, a produtividade do bananal também aumenta devido a maior quantidade de cachos colhidos (Cayón et al., 2004; Cavalcante et al., 2014; Ulloa Cortazar et al., 2017; Prata et al., 2018).

Os frutos apresentaram valores médios entre 26,78 e $27,83 \mathrm{~cm}$ para o comprimento, e entre 49,89 e 51,18 mm para o diâmetro, tanto em monocultivo quanto em consórcio. Os resultados são contrários aos obtidos por Moura et al. (2002) que verificaram maiores comprimento e diâmetro dos frutos para a bananeira comprida verdadeira, quando se utilizou espaçamentos menos adensados, sendo estatisticamente inferiores ao deste estudo.

O comprimento do fruto é um importante atributo de qualidade, considerado pelos consumidores no ato da compra, o qual deve apresentar pouca variação entre as unidades, para que a escolha não seja afetada (Chitarra \& Chitarra, 2005). Conforme Basan (2016), os consumidores de maior poder aquisitivo são mais exigentes que os da média e baixa renda em termos de tamanho dos frutos (diâmetro e comprimento), o que significa que os consumidores de alta renda estão dispostos a pagar maiores preços pela qualidade da banana. Com isso, os agricultores e comerciantes podem aumentar a lucratividade, considerando os atributos de qualidade.

Na Tabela 3, são apresentados os resultados referentes à qualidade química de bananas provenientes da segunda penca de cada cacho, no grau de maturação V, ou seja, frutos com coloração amarela e extremidades ainda verdes (Carvalho et al., 2011). Observa-se que não houve diferenças significativas entre tratamentos para todas as características analisadas.

As bananas apresentaram $\mathrm{pH}$ 4,86, em média, nos diferentes arranjos de plantio em monocultivo e consórcio com açaizeiro solteiro, caracterizando a natureza ácida da polpa. Segundo Bleinroth (1985) o pH varia de 4,2 a 4,7 para bananas maduras e de 5,0 a 5,6 quando verdes. Resultados semelhantes foram encontrados por Bezerra \& Dias (2009) para as cultivares Thap Maeo e Caipira com pH de 4,9, e Fhia 21 com 4,8.

A acidez total titulável (AT) apresentou média de 0,53\% de ácido málico, sem diferir estatisticamente entre os tratamentos, estando dentro da faixa de $0,19 \%$ a $0,67 \%$ sugerida por Cerqueira et al. (2002). A acidez é atribuída aos ácidos orgânicos dissolvidos nos vacúolos das células dos frutos, os quais, juntamente com os açúcares, contribuem para o aroma e sabor característico (Chitarra \& Chitarra, 2005).

O teor de sólidos solúveis totais (SST) variou de $16,01 \%$ a $18,17 \%$, com média de $17,23 \%$. Este resultado se assemelha aos genótipos Bucaneiro, Calipso e PV03-44 com SST entre 16,82\% e 18,62\%, obtidos por Cerqueira et al. (2002). Segundo Bleinroth (1985), o valor máximo de SST alcançado para as diversas variedades de banana é de $27 \%$, podendo diminuir após a completa maturação da fruta. A redução no teor de SST após o valor máximo pode estar associada ao consumo de açúcares, devido o maior metabolismo respiratório, e ao crescimento de microrganismos (Pizato et al., 2013), o que pode indicar

Tabela 3 - Valores médios de pH, acidez titulável (AT), sólidos solúveis totais (SST) e relação sólidos solúveis totais/acidez titulável (RATIO) de banana terra, cv. D'angola, em monocultivo e consórcio com açaizeiro solteiro em diferentes arranjos de plantio. Rio Branco, AC. 2014

\begin{tabular}{|c|c|c|c|c|}
\hline Espaçamentos & $\mathrm{pH}$ & $\mathrm{AT} \%$ & $\mathrm{SST} \%$ & RATIO \\
\hline Bananeira (3 x $3 \mathrm{~m})$ & $4,81 \mathrm{a}$ & $0,50 \mathrm{a}$ & $17,73 \mathrm{a}$ & $35,21 \mathrm{a}$ \\
\hline Bananeira ( $3 \times 2 \mathrm{~m}) \times$ açaizeiro solteiro $(3 \times 4 \mathrm{~m})$ & $4,87 a$ & $0,53 a$ & $18,15 a$ & $35,06 a$ \\
\hline Bananeira ( $3 \times 3 \mathrm{~m}) \times$ açaizeiro solteiro $(3 \times 4 \mathrm{~m})$ & $4,84 \mathrm{a}$ & $0,56 a$ & $18,17 \mathrm{a}$ & $32,53 a$ \\
\hline Bananeira ( $4 \times 2 \times 2 \mathrm{~m}) \times$ açaizeiro solteiro $(6 \times 3 \mathrm{~m})$ & $4,86 a$ & $0,50 \mathrm{a}$ & $16,07 a$ & $32,60 \mathrm{a}$ \\
\hline Bananeira $(4 \times 2 \times 2 \mathrm{~m}) \times$ açaizeiro solteiro $(4 \times 2 \times 3 \mathrm{~m})$ & $4,90 \mathrm{a}$ & $0,54 \mathrm{a}$ & $16,01 \mathrm{a}$ & $30,51 \mathrm{a}$ \\
\hline CV (\%) & 1,55 & 11,38 & 10,38 & 18,82 \\
\hline Média geral & 4,86 & 0,53 & 17,23 & 33,18 \\
\hline
\end{tabular}

Médias seguidas de mesma letra não diferem entre si pelo teste de Tukey $(p>0,05)$. 
o início do estádio de senescência da fruta (Silva et al., 2017).

Resultados estatisticamente superiores foram verificados por vários autores para cultivares do mesmo grupo genômico (Cerqueira et al., 2002; Bezerra \& Dias, 2009). Esta variação nos teores de SST pode ocorrer de acordo com a cultivar, prática de manejo adotada, densidade de plantas, clima (Chitarra \& Chitarra, 2005), e através do grau de maturação, pois o amido presente no fruto é hidrolisado em açúcares solúveis, tais como glicose, sacarose e frutose Sanaeifar et al. (2016), elevando assim, o teor de SST.

O valor de SST é um importante indicador de doçura, e consequentemente da banana, já que $85-90 \%$ das substâncias dissolvidas em água é constituída por açúcares. A determinação do SST auxilia na colheita, desde que associado a outras características como tamanho do fruto, permitindo, dessa forma, frutos com melhor qualidade comestível in natura e maior rendimento da matéria prima para agroindústria (Chitarra \& Chitarra, 2005).

A relação sólidos solúveis totais com acidez total titulável (RATIO), apresentou média de 33,18, sendo estatisticamente inferior a obtida por Bezerra \& Dias (2009), com 82,90. Porém, está condizente com os 33,70 encontrado para o genótipo Preciosa (PV42-85) por Cerqueira et al. (2002).

\section{CONCLUSÕES}

O cultivo consorciado de bananeira terra, cv. D'angola, com açaizeiro solteiro em diferentes arranjos de plantio não influencia no crescimento e desenvolvimento, características de produção, qualidade físico-químicas de banana no primeiro ciclo, com exceção do perímetro do pseudocaule, produtividade e quantidade de folhas ativas na colheita.

A produtividade é maior em plantios mais adensados, independentemente do sistema de cultivo (monocultivo ou consórcio).

\section{LITERATURACITADA}

ALVES, E.P.; SILVA, M.L.; OLIVEIRA NETO, S.N. et al. Economic analisys of a coffee-banana system of a family - based agriculture at the atlantic Forest Zone, Brazil. Ciência e

Agrotecnologia, v.39, n.3, p.232-239, 2015.
ARANTES, A.M.; DONATO, S.L.R.; SILVA, S.O. Relação entre características morfológicas e componentes de produção em plátanos.

Pesquisa Agropecuária Brasileira, v.45, n.2, p.224-227, 2010.

BASAN, R.J.P. Consumer preference of table banana quality by income groups in the philippines: hedonic price analysis. Asian

Journal of Agriculture and Development, v.13, n.2, p.20-33, 2016.

BEZERRA, V.S.; DIAS, J.S.A. Avaliação físicoquímica de frutos de bananeiras. Acta Amazonica, v.39, n.2, p.423-428, 2009.

BLEINROTH, E.W. Matéria prima. In: MEDINA, J.C.; BLEINROTH, E.W.; MARTIN, Z.J.; MORETTI, V.A. Banana: cultura, matéria-prima, processamento e aspectos econômicos. 2.ed. rev. e ampl. Campinas: Instituto de Tecnologia de Alimentos, 1985, p.133-196.

BOLFARINI, A.C.B.; JAVARA, F.S.; LEONEL, S.; LEONEL, M. Crescimento, ciclo fenológico e produção de cinco cultivares de bananeira em condições subtropicais. Revista Raízes e Amidos Tropicais, v.10, n.1, p.74-89, 2014.

CARVALHO, A.V.; SECCADIO, L.L.; MOURÃO JÚNIOR, M.M.; NASCIMENTO, W.M.O. Qualidade pós-colheita de cultivares de bananeira do grupo 'maçã', na região de BelémPA. Revista Brasileira de Fruticultura, v.33, n.4, p.1095-1102, 2011.

CAVALCANTE, M.J.B.; ANDRADE NETO, R.C.; LEDO, A.S. et al. Manejo fitotécnico da bananeira, cultivar D'angola (AAB), visando ao controle da sigatoka-negra. Revista

Caatinga, v.27, n.2, p.201-208, 2014.

CAYÓN, S.G.; VALENCIA, M.J.A.; MORALES, O.H.; DOMÍNGUEZ, A. Desarrollo y producción del plátano Dominico-Hartón (Musa AAB Simmonds) em diferentes densidades y arreglos de siembra. Agronomía Colombiana, v.22, n.1, p.18-22, 2004. Disponível em: <http:// www.redalyc.org/articulo.oa?id=180317823003> . Acesso em: 10 out. 2018. 
CERQUEIRA, R.C.; SILVA, S.O.; MEDINA, V.M. Características pós-colheita de frutos de genótipos de bananeira (Musa spp.). Revista Brasileira de Fruticultura, v.24, n.3, p.654-657, 2002. Disponível em: <http://www.scielo.br/pdf/rbf/v24n3/ 15104.pdf > . Acesso em: 10 out. 2018.

ChitarRA, M.I.; CHITARRA, A.B. PósColheita de frutos e hortaliças: fisiologia e manuseio. 2.ed. rev. e ampl. Lavras: UFLA, 2005. 785p.

COELHO, E.F.; OLIVEIRA, R.C.; PAMPONET, A.J.M. Necessidades hídricas de bananeira tipo Terra em condições de tabuleiros costeiros.

Pesquisa Agropecuária Brasileira, v.48, n.9, p.1260-1268, 2013.

\section{DANTAS, D.J. Características}

agronômicas de cultivares de bananeira em três ciclos de produção e reação de genótipos a Cosmopolites sordidus no Vale do Açu-RN. 2010. 83 f. Tese (Doutorado em Fitotecnia) - Departamento de Ciências Vegetais, Universidade Federal Rural do Semi-Árido, Mossoró, 2010.

FARIA, H.C.; DONATO, S.L.R.; PEREIRA, M.C.T.; SILVA, S.O. Avaliação fitotécnica de bananeira tipo terra sob irrigação em condições semi-áridas. Ciência e Agrotecnologia, v.34, n.4, p.830-836, 2010.

FERREIRA, C.F.; SILVA, S.O.; AMORIM, E.P.; SANTOS-SEREJO, J.A. (Eds). O agronegócio da banana. Brasília: Embrapa, 2016a. p.137-170.

FERREIRA, D.F. Sisvar: a computer statistical analysis system. Ciência e Agrotecnologia, v.35, n.6, p.1039-1042, 2011.

FERREIRA, T.M.C.; VASCONCELOS, M.; CANTÃO, B.P. et al. Uso da terra com base no sistema agroflorestal: um estudo no município São Domingos do Capim, Pará. Revista de

Ciências Agroambientais, v.14, n.2, p.9399, 2016b.

\section{GÜERERE-PEREIRA, P.; MARTÍNEZ, L.;}

FUENMAYOR, L. Efecto del deshoje inducido sobre la productividad del plátano (Musa AAB) cv. Hartón y la incidência de sigatoka negra (Mycosphaerella fijiensis Morelet). Revista de la Facultad de Agronomía, v.25, n.4, p.636-648, 2008.
IBGE. Banco de tabelas estatísticas. Disponível em: < https://sidra.ibge.gov.br/home/ ipca/brasil>. Acesso em: 12 mar. 2018.

MOURA, R.J.M.; SIVA JÚNIOR, J.F.S.; SANTOS, V.F.; GOLVEIA, J. Espaçamento para o cultivo da bananeira comprida verdadeira (Musa AAB) na Zona da Mata Sul de Pernambuco ( $1^{\circ}$ ciclo).

Revista Brasileira de Fruticultura, v.24, n.3, p.697-699, 2002.

NOGUEIRA, S.R.; ANDRADE NETO, R.C.; NASCIMENTO, G.C.; GONZAGA, D.S.O.M. (Eds). Sistema de produção de banana para o estado do Acre. Rio Branco, AC: Embrapa Acre, 2017. (Sistema de produção, 7). Disponível em: <https://www.spo.cnptia.embrapa.br>. Acesso em: 09 fev. 2019.

PIZATO, S.; CORTEZ-VEGA, W.R.; PRENTICEHERNÁNDEZ, C.; BORGES, C.D. Efeito da aplicação de diferentes revestimentos comestíveis na conservação de maçãs 'Royal Gala' minimamente processadas. Semina: Ciências Agrárias, v.34, n.1, p.253-264, 2013.

PRATA, R.C.; SILVA, J.; LIMA, Y.B. et al. Densidade de plantio no crescimento e produção de plátano cv. D’Angola na Chapada do Apodi.

Revista Agropecuária Técnica, v.39, n.1, p.15-23, 2018.

SALES, F.E.; ARAUJO, J.B.S.; BALDI, A. Sistemas agroflorestais e consórcios no Estado do Espírito Santo: relatos de experiências. Vitória: Incaper, 2018. 22p.

(Documentos, 254).

SANAEIFAR, A.; BAKHSHIPOUR, A.; DE LA GUARDIA, M. Prediction of banana quality indices from color features using support vector regression. Talanta, v.148, n.1, p.54-61, 2016.

SCARPARE FILHO, J.A.; KLUGE, R.A. Produção de bananeira 'nanicão' em diferentes densidades de plantas e sistemas de espaçamento. Pesquisa Agropecuária Brasileira, v.36, n.1, p.105113, 2001.

SILVA, B.; OLIVEIRA, T.; PINTO, E. et al. Efeito de diferentes revestimentos sobre o escurecimento enzimático em maçã. Revista Agrarian, v.10, n.38, p.355-362, 2017. 
SILVA, M.J.R.; SANTOS, L.S.; PEREIRA, M.C. et al. Produção e qualidade de fruto de bananeiras 'Pacovan Ken' e genótipo PA94-01 por dois ciclos produtivos. Revista Ceres, v.63, n.6, p.836-842, 2016.

SILVA, S.O.; PIRES, E.T.; PESTANA, R.K.N. et al. Avaliação de clones de banana cavendish.

Ciência e Agrotecnologia, v.30, n.5, p.83237, 2006.
ULLOA CORTAZAR, S.M.; WOLF, E.D.; ARMENDARIZ GONZALEZ, I. Effect of plant density on growth and yield in Barraganete plantain (Musa paradisiaca (L.) AAB cv. Curare enano) for a single harvest cutting in Provincia de Los Ríos, Ecuador. Acta Agronómica, v.66, n.3, p.367-372, 2017.

Recebido para publicação em 6/1/2019 e aprovado em 22/3/2019. 